\title{
Using iPods \& iPhones for Hands on Programs (HOPs) In Mechanical Engineering Laboratories
}

\author{
Darrel Doman, Ted Hubbard, \\ Mechanical Engineering Department \\ Dalhousie University, Halifax, Nova Scotia, \\ Canada, B3J 2X4 \\ ted.hubbard@dal.ca
}

\begin{abstract}
This paper presents a new laboratory experiment recently conducted at Dalhousie University where Apple iPod Touches and iPhones were used to provide Hands On Programs (HOPs). Both iPod Touches and iPhones contain accurate 3-axis accelerometers that can be used to take real measurement of vibrating systems. The Apple App Store contains a number of applications that utilize the built-in accelerometers. A basic free App was downloaded by the students. The department rapid prototyped a simple iPod / iPhone holder attached to a cantilevered vibrating beam and after a brief familiarization period the students collected the raw data and emailed themselves the results over the classroom Wi-Fi. The students then analyzed the data using an instructor-supplied spreadsheet. This lab allowed the students to be introduced to such concepts as: data collection, vibration of continuous systems, resonant frequencies, quality factor and damping, and finally data analysis.
\end{abstract}

\section{Introduction}

The Hands On Programs (HOPs) at Dalhousie seeks activities having the following academic impact:

1. Hands-on experience with technology and realworld parts.

2. Small-group work with a targeted objective promotes student engagement, leading to higher academic outcomes.

From a pedagogical perspective, HOPs touches on key aspects which are known to improve student outcomes. Though there has been much research on the topic of controlling factors in university education, the works by Astin [1] and Light [2][3] show that two of the most influential factors on student outcomes are interactions with 1) other students and with 2) faculty. Light's findings echoed Astin's but were phrased as student engagement. In short, those students that are engaged, or are actively involved, in the course material exhibit higher retention rates and overall better grades. Since HOPs uses small groups of student who cooperatively work on the part they have a high degree of peer interaction.

\section{2 iPod Touch / iPhone}

\subsection{Mobile Devices}

It is sometimes difficult to design an experiment where students acquire hard numerical data without expensive equipment to acquire said data. Moreover that expensive equipment tends to do most of the work and isolates the students from the actual data acquisition Both iPod Touches and iPhones contain accurate 3 -axis accelerometers that can be used to take real measurement of vibrating systems.

Polling of a Machine Design class indicated that approximately $33 \%$ of the class had either an Apple iPod Touch or an Apple iPhone. Thus small groups of approximately three to four students could be formed from the existing student owned pool of devices. Such a laboratory experiment offers a number of advantages:

1. It leverages existing infrastructure of student owned devices, minimizing capital costs. The total cost was $\sim \$ 30$ per setup including the cost of purchasing 1 instructor iPod Touch.

2. High level student involvement and interest.

3. Expandability to other types of measurements and other Engineering/Science courses.

\subsection{Accelerometer Apps}

The Apple App Store contains a number of applications that utilize the accelerometers. The accelerometer is 3-axis: $\mathrm{X}, \mathrm{Y} \& \mathrm{Z}$. Typically if the mobile device is held in the hand $\mathrm{X}$ is left \& right, $\mathrm{Y}$ is up $\&$ down and $\mathrm{Z}$ is far $\&$ near as shown in Figure 1. 


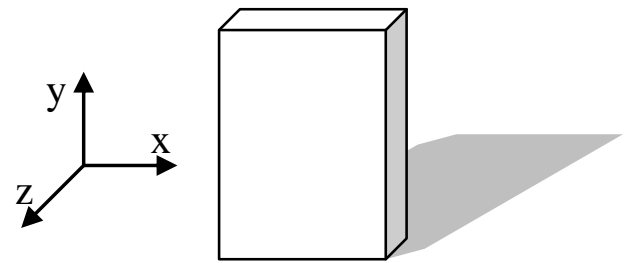

Figure 1. Axes orientation as seen if the mobile device is held in the hand.

In order to perform the lab students must have:

1. Apple iPod Touch or iPhone

2. Apple iTunes account to install the App

3. Email enabled to send the data

The last point regarding email is important as it was discovered that a surprisingly large percent of students had no email setup on their own device. It is important to notify students of this requirement in advance. Lastly, while a Wi-Fi enabled room is not strictly required during the operation of the lab, it is required to download the App and to email the results.

Apps range in price from free to more than $\$ 100$. For this laboratory we chose iSeismometer which is free. ISeismometer has all the basic functions needed. Note: Do not confuse it with other similarly named Apps: "iSeismometer." (note period!), "iSeismometer (shake detector)", "iSeismograph" etc. Another suggested possibility for this lab was Vibrations at \$4.99. It has more features and a better frequency display.

Once students have installed iSeismometer, they start the App and oscillate the iPod / iPhone. They play with the App, seeing how gently shaking their iPod / iPhone produces a signal. Students should be familiar with the Pause and Play operations. iSeismometer stores 10 seconds of data and the last 3 seconds are visible on the screen; when paused users can scroll the screen left and right. Within the Setting tab, students should make sure the Sample Rate is set to $100 \mathrm{~Hz}$. Students should also make sure the High Pass Filter is ON. This enables measurement of higher frequency oscillations while discarding the lower frequency changes in device orientation. Alternatively, if measurement of orientation rather than acceleration is desired, this should be switched to OFF. Students then practice emailing themselves a sample data set:

- Check Data Transfer (stacked disk symbol)

- Go to Send via Email section

- Enter email address

- Select Send as CSV: comma separated variables: $\mathrm{X}, \mathrm{Y}, \mathrm{Z}$

- Exit Mail using the home button and restart iSeismometer
The total time required for downloading the App and becoming familiar with its use was less than 10 minutes.

\section{Laboratory Preparation}

\subsection{Holder}

The experimental apparatus consists of: a rapid prototyped holder, an aluminum meter stick with two $1 / 4$ " holes near the end, an elastic band, and a student supplied iPod / iPhone. The holder is bolted to the meter stick via two $1 / 4-20$ bolts and wing nuts. The ruler is oriented such that the $0 \mathrm{~cm}$ mark is cantilevered over a table or desk and the $100 \mathrm{~cm}$ mark is held in the hand on the table or desk .

The iPod / iPhone holder was rapid prototyped from ABS. A solid model of the holder may be found at: http://myweb.dal.ca/tjhubbar/iPod_iPhone_holder.par Wooden holders could also be constructed if rapid prototyping is not available. The holder is a $25 / 8$ " $\mathrm{x}$ $47 / 8$ " $x$ 3/4" rectangular box as shown in Figure 2. The walls are $1 / 8$ " thick, leaving an ample interior space of $23 / 8$ " x $45 / 8$ " x 1/2". There are two $1 / 4$ " holes at each end spaced approximately 6" apart to secure the holder to a meter stick. There is an overhang / pocket at one end; the pocket is mounted towards the end of the ruler. There are two notches on the sides towards the end opposite the pocket.

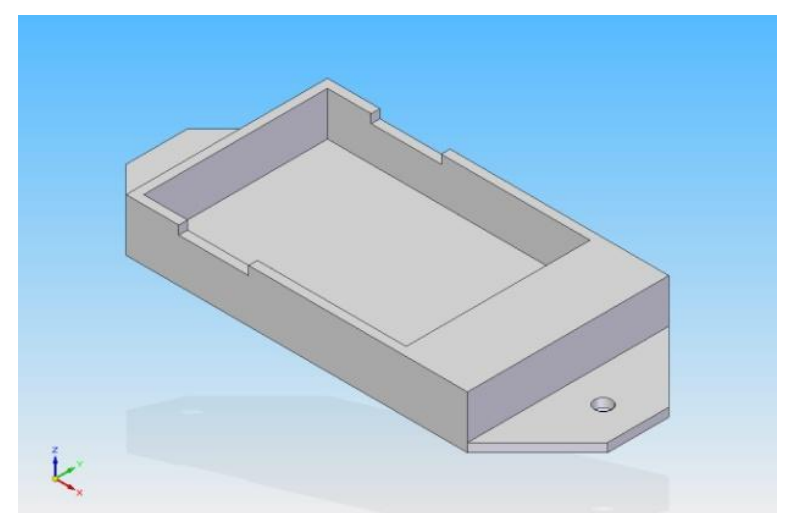

Figure 2. Rapid prototyped iPod holder. The holder is bolted onto a meter stick, overhang/pocket toward the far end.

The cost per holder was approximately $\$ 20$, the cost per meter stick was approximately $\$ 5.25$ setups were fabricated and 1 iPod Touch purchased for the instructor. The total cost was $\sim \$ 30$ per setup. 


\section{Laboratory}

\subsection{Mounting in the Holder}

A copy of the student manual can be found at http://myweb.dal.ca/tjhubbar/iPod_manual.pdf Students sign a consent form saying they will be careful not to drop their own iPod / iPhone They then get a short instruction manual, and a brief safety lecture. The top end of the iPod / iPhone is slid into the pocket in the holder, towards the end of the ruler, home button closer to the notches. The holder is made a little larger than most iPods / iPhones (minus cases), so the device will likely be loose and may rattle around. If so, small strips of paper can be folded and inserted snugly between the device and holder.

Next the elastic band provided is stretched to ensure it is not damaged. The doubled-up elastic band is slid over the holder and the iPod / iPhone so that the bands rest in the two notches in the holder sides. It may be necessary to move the bands around to press soft keys / home button. Students next carefully rotate the iPod / iPhone $360^{\circ}$ until they are confident that the iPod / iPhone cannot move around or fall out.

\subsection{Acceleration Measurement}

The free end of the ruler is then clamped by hand onto a table; keeping at least $30 \mathrm{~cm}$ of the ruler on the table. One person firmly holds the ruler down with two hands: one at the far end and one at the table edge. It is important to clamp right at the edge of the table. A second person gently lifts the holder up a few $\mathrm{cm}$, and releases. The iPod records its motion and displays the results in real time. Figure 3 shows actual data taken by students formatted similarly to iSeismometer screen layout. Large $\mathrm{Z}$ signals should be observed as well as smaller Y signals, but no $\mathrm{X}$. (The Y signal comes from the centripetal motion). The vibrations should be small; a few $\mathrm{cm}$ is sufficient and should never exceed $10 \mathrm{~cm}$. If the ruler is making a tapping noise, the ruler is not being clamped close to the table edge. Under no circumstances should the beam be vibrated so much that the iPod / iPhone is at risk of falling out or that the beam is permanently bent.

\subsection{Resolution and Repeatability}

The type of motion sensor varies by Apple product: the iPod Touch $2 \& 3$ and iPhone 3 have a 3 -axis accelerometer only, while the iPod Touch 4 and iPhone 4 have both a 3 -axis accelerometer and a 3 -axis gyroscope. Apple does not provide detailed specifications for their accelerometers, but they are

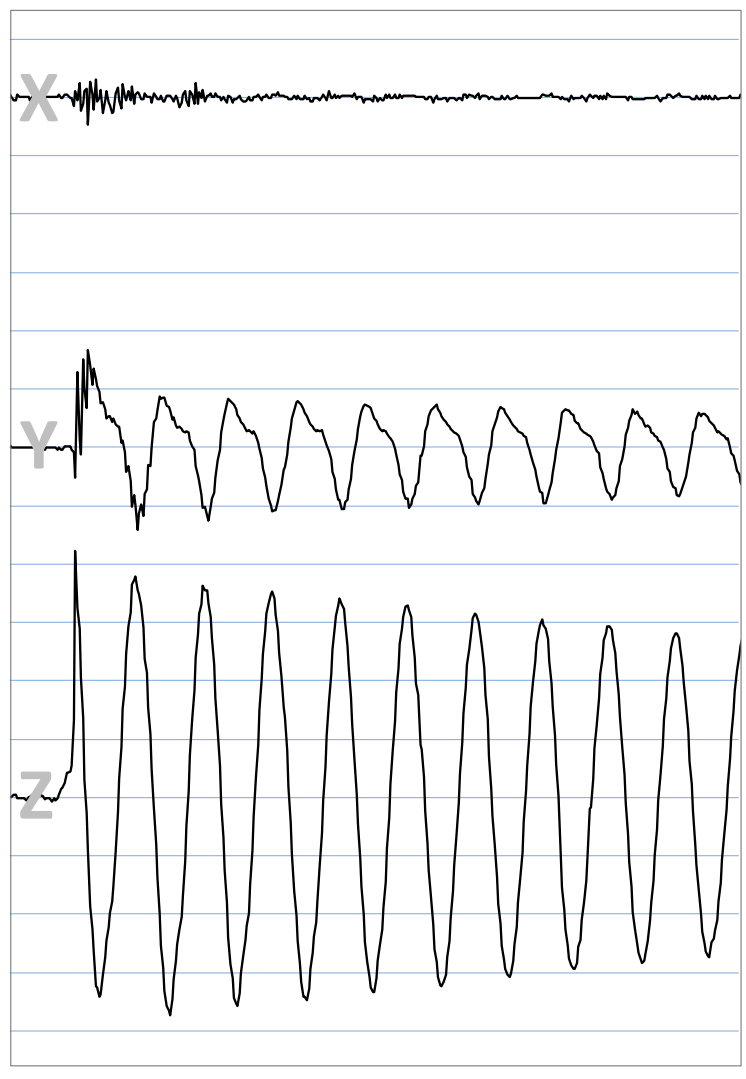

Figure 3. Actual data taken by students during lab, formatted similarly to ISeismometer screen layout.

reported by Chipworks [5] and others to be similar to the MEMS-based STMicroelectronics LIS331DL [6] which is rated for $\pm 2.3 \mathrm{~g}$ with a resolution of \pm 0.018 $\mathrm{g}$, or approximately $\pm 1 \%$ resolution. Correspondingly, the gyroscope is reported to be similar to the MEMS based STMicroelectronics L3G4200D [7].

In this particular laboratory, the magnitude of the acceleration is not directly measured but rather the frequency of acceleration. Both of the Apps tested in the lab iSeismometer and Vibration include built-in FFT capabilities, but the resolution is relatively coarse and did not produce satisfactory results. More accurate results were obtained by importing the data into a simple excel spreadsheet and counting the number of periods over a known time interval. For this the sampling rate and intrinsic time base must be known. The maximum sampling rate of the accelerometer is $100 \mathrm{~Hz}$ and many Apps are set to this by default. However, the sampling rate can be slowed down if the processor is loaded by background processes such as mail and notifications. In practise the nominal sample rate of $100 \mathrm{~Hz}$ routinely fluctuated from 100 to $96 \mathrm{~Hz}$ during testing. This can be improved by reducing the sample rate to say $50 \mathrm{~Hz}$, but there is still some variation. Another possibility is to turn off the 
real time animation, but this would defeat the purpose of the hands-on nature of the lab. The data sent by the application not only includes $\mathrm{X}, \mathrm{Y}, \mathrm{Z}$ data but also a fourth column with time base updates; this could be used to recalibrate the time base.

In the end, none of these measures were deemed necessary, as the few percent errors in time base were not significant compared to the uncertainties in the lab setup such as dimensions and weights. Furthermore, by taking long samples over multiple periods $(10+)$ and repeating the measurements, students were able to average out most of the variations.

To quantify the repeatability of the measurements, the instructor measured the resonant frequency of a 30 $\mathrm{cm}$ cantilevered beam 10 times. The mean value was $5.81 \mathrm{~Hz}$ with a standard deviation of $0.05 \mathrm{~Hz}$ or $0.9 \%$ of the mean. The maximum deviation from the mean for any of the 10 measurements was $1.2 \%$. In summary, the student measured results should be accurate to within a few percent of the actual values.

\subsection{Student Results}
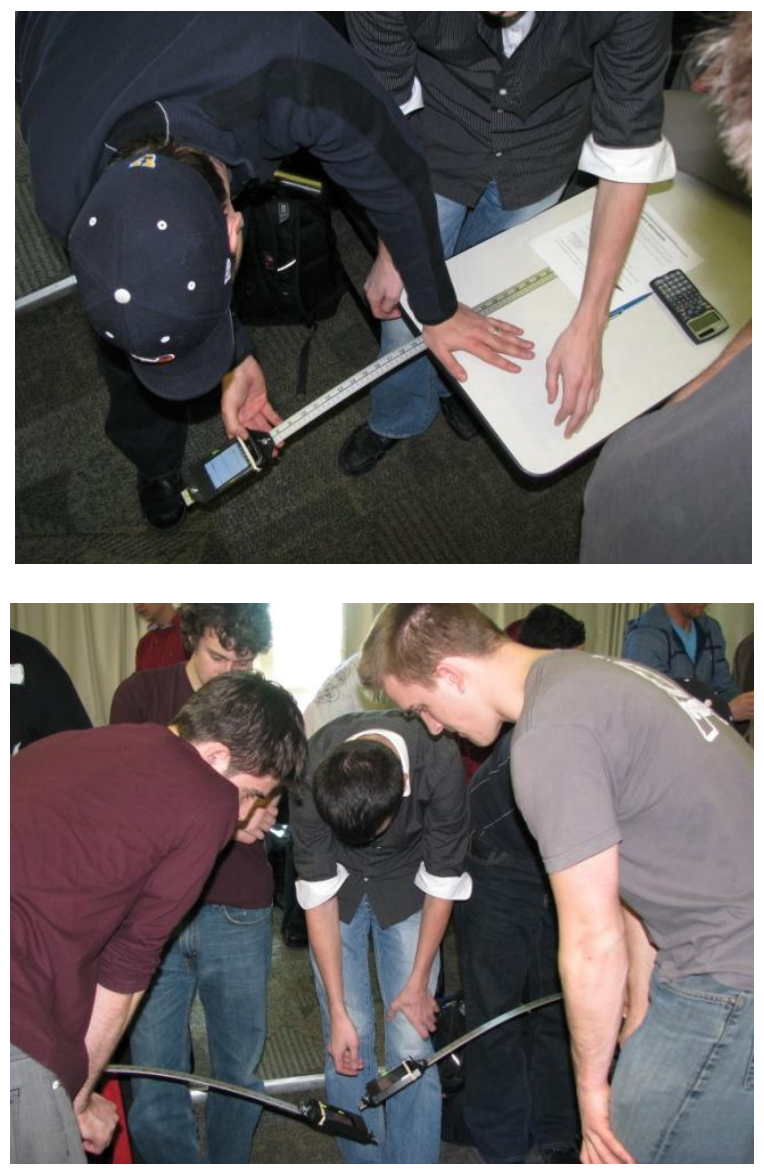

Figure 4. Photos from iPod / iPhone vibrations laboratory.
Figure 4 shows photos taken during the vibrations laboratory. The students repeat the basic frequency measurement for shorter and shorter lengths, making the resonance frequency go up. Two data points are measured at each of the following clamping locations: $60,50,40,30$ and $20 \mathrm{~cm}$ from the ruler end. The students email the results to themselves after each test and analyze the data using an instructor supplied excel sheet to determine the resonant frequency in $\mathrm{Hz}$.

18 teams of three students participated: each was to make two measurements at 5 different lengths for 10 measurements $=180$ measurements. A total of 169 of 180 measurements were actually collected by the class: 15 teams got 10/10, 1 team got 9/10, 2 teams got $5 / 10$. Figure 5 plots the measured frequencies fit by a power law. The length was measured from the center of mass of the iPod / iPhone $(8.5 \mathrm{~cm}$ from the $0 \mathrm{~cm}$ mark on the ruler). Neglecting the mass of the beam, the expected result would be proportional to $\mathrm{L}^{-1.5}$. The fitted exponent was $\mathrm{L}^{-1.44}$ with an $\mathrm{R}^{2}$ value of 0.99 . See below for possible causes to this discrepancy.

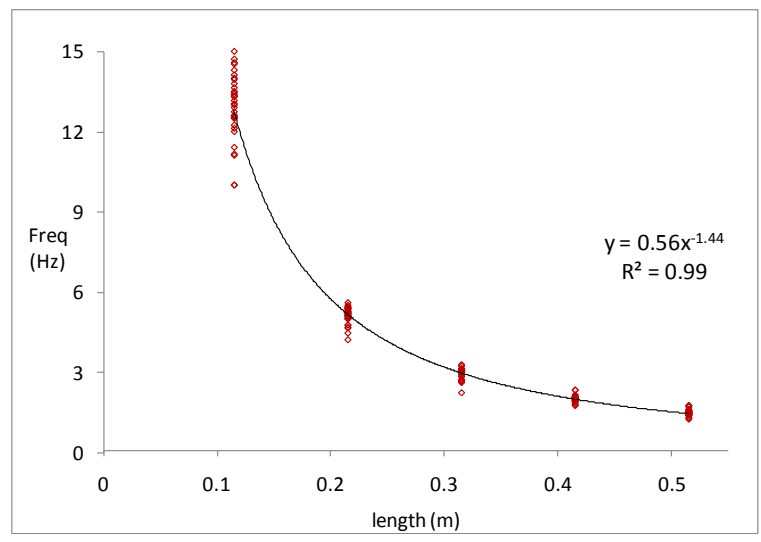

Figure 5. Student frequency measurements plotted versus length (measured from device COM).

To quantify the repeatability of the within-team measurements, the standard deviation in the pair of measured values of frequency of the $30 \mathrm{~cm}$ beam for each team was compared. The average standard deviation within a team's results was $2.2 \%$. The spread in inter-teams measured values was significantly higher, Figure 6 Shows a histogram of results for the $30 \mathrm{~cm}$ beam. The average standard deviation of inter-teams results was $5.9 \%$. This increase in variability is likely due to the varying weights of the student's mobile devices.

Approximately two thirds of the class had iPhones, versus approximately a third who had iPod Touches. The iPhone 3 and 4 are essentially the same weight (135g \& $137 \mathrm{~g}$ ) but the iPod touches are significantly lighter (115g for the Touch $2 \& 3$ and $101 \mathrm{~g}$ for the 
Touch 4). Additionally the presence or absence of a case can change the mass by as much as $20 \mathrm{~g}$. The weight range varies by as much as $15 \%$ from the mean; as the frequency depends on the square root of the mass, this could result in as much $8 \%$ difference in inter-team frequencies.

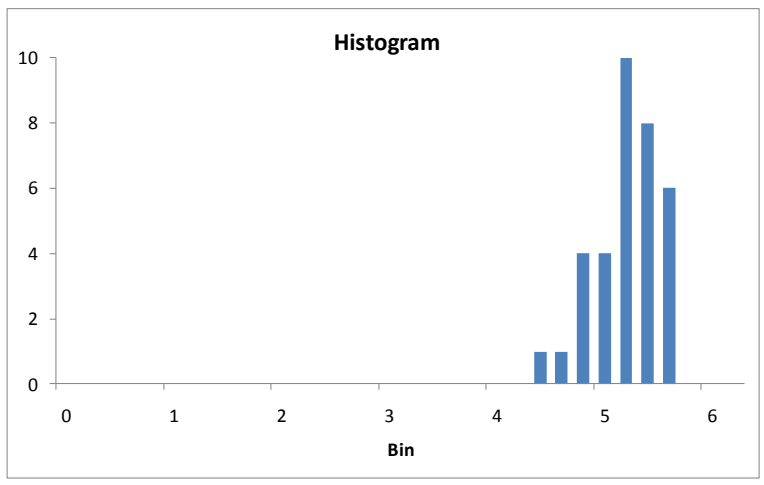

Figure 6. Histogram of inter-team student frequency measurements, length $=30 \mathrm{~cm}$.

Mean $=5.25 \mathrm{~Hz}$, St. Dev. $=0.35 \mathrm{~Hz}=5.9 \%$

\subsection{Coupled Oscillators}

For students who finished earlier a demonstration setup was made available where two side by side yard sticks were coupled with an elastic band, and students could see and measure coupled oscillators. The setup is shown in Figure 7, note the counterweights on the left. Measured data is shown in Figure 8.

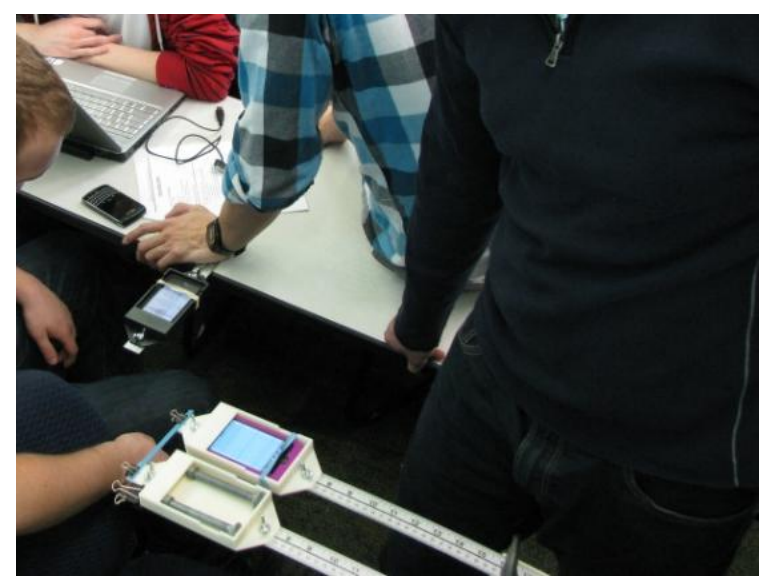

Figure 7. Coupled oscillators setup.

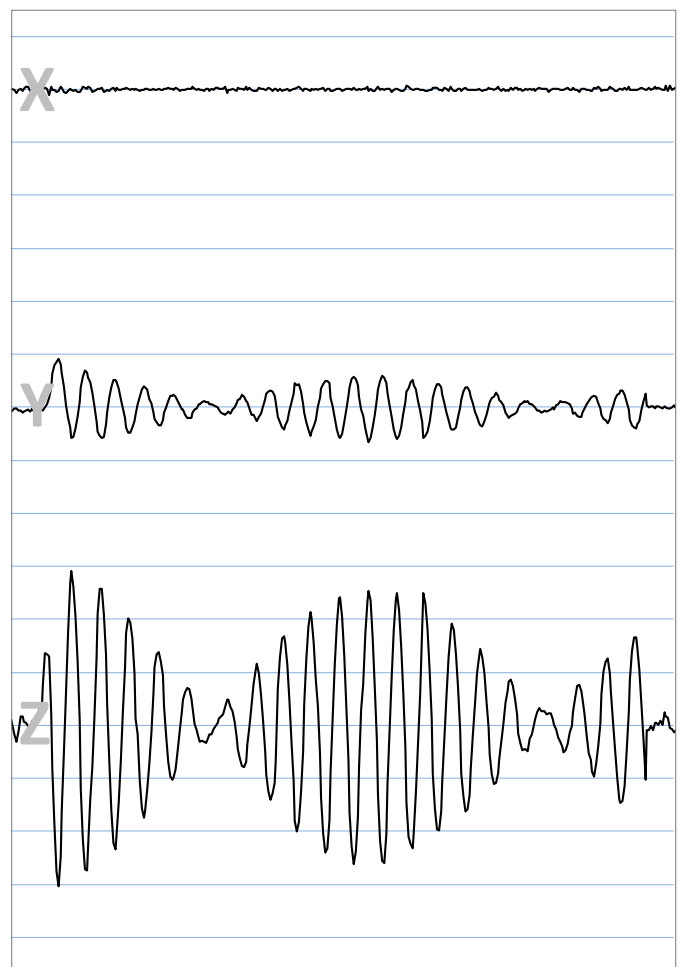

Figure 8. Coupled Oscillators data.

\section{Student Feedback}

Students were polled after completing the lab and asked to agree or disagree with 5 statements. Students would reply to each statement with one of five possible scores: $1=$ Very much disagree, $2=$ Somewhat disagree, 3 = Unsure, $4=$ Somewhat agree, $5=$ Very much agree. The higher the numerical score the more in agreement the students were with the statement. The statements and the results of the survey including average response out of a possible 5 are shown in Table 3 indicating a high level of interest in the lab. The lab has also proved popular with nonundergraduates. All members of the department were invited to bring their own iPods/iPhones; participants included graduate students, staff and even faculty and senior administrators. 
Table 3. Student questionnaire responses

\begin{tabular}{|l|l|l|l|l|l|l|}
\hline & \multicolumn{5}{|c|}{$\begin{array}{c}\text { Number of } \\
\text { Responses }\end{array}$} \\
\hline \multicolumn{1}{|c|}{ Statements } & 1 & 2 & 3 & 4 & 5 & Avg \\
\hline $\begin{array}{l}\text { The lab was } \\
\text { engaging and } \\
\text { peaked my interest }\end{array}$ & 1 & 3 & 1 & 15 & 38 & $\mathbf{4 . 5}$ \\
$\begin{array}{l}\text { The lab helped me } \\
\text { apply theory to a } \\
\text { practical problem }\end{array}$ & 1 & 2 & 4 & 19 & 32 & $\mathbf{4 . 4}$ \\
\hline $\begin{array}{l}\text { Use of the iPods } \\
\text { allowed for more } \\
\text { hands-on work }\end{array}$ & 2 & 1 & 3 & 17 & 35 & $\mathbf{4 . 4}$ \\
\hline $\begin{array}{l}\text { Overall, this lab } \\
\text { increased } \\
\text { understanding of the } \\
\text { topic }\end{array}$ & 1 & 3 & 9 & 20 & 25 & $\mathbf{4 . 1}$ \\
\hline $\begin{array}{l}\text { I would like more } \\
\text { labs of this type }\end{array}$ & 2 & 3 & 0 & 14 & 39 & $\mathbf{4 . 5}$ \\
\hline
\end{tabular}

\section{Other Classes}

While HOPs was first used to help explain and demonstrate mechanical vibrations, the iPod / iPhone has many other potential pedagogical uses. Still using the iSeismometer App, a second year ENGI 2400 Mechanics II class investigated the coefficient of friction of various surfaces. By turning the High Pass Filter OFF, the orientation of the iPod / iPhone is recorded in three dimensions. For example, holding the unit vertically results in a -1 g reading in the $\mathrm{Y}$ direction while holding it at $45^{\circ} \mathrm{CCW}$ in the vertical plane results in a $-1 / \sqrt{ } 2 \mathrm{~g}$ reading in the $\mathrm{X}$ and $\mathrm{Y}$ directions. Students used the iPod / iPhone in the holders and placed them on various hard surfaces such as text books, wooden boards, etc. The surfaces were tipped up while holding one end fixed and acceleration data was recorded. As soon as the iPod / iPhone began to slip the data measurement was stopped. By using the acceleration data the ramp angle $\theta$ at which tipping occur is found, from which the static coefficient of friction is determined.

Longer term the goal is to have a Dalhousie Engineering/Science App that can be customized to the need of courses taught here.

Moving beyond the accelerometer and the iSeismometer app there is an even wider range of long-term teaching possibilities given the powerful functionality of the iPod / iPhone. It could be possible, with the built in cameras and customized apps, to take pictures of experiments and perform image processing techniques to deliver on-demand experimental results. This would be directly applicable to many the introductory Physics courses as well as Chemistry, Biology, Computer Science, etc.

\section{Conclusion}

As part of the Hands on Program (HOPs), this paper presented a laboratory in Mechanical Engineering using iPod Touches and iPhones. The devices were found to capable of measure vibration frequencies in a laboratory setting to within a few percent. Students were able to physically experience and measure vibrations using their own mobile devices. Future engineering students will come into the program with ever more capable mobile devices that have excellent instrumentation hidden inside them, so the possibilities for this kind of work should expand.

\section{Acknowledgments}

The authors would like to thank Dr. M.R. Kujath for his assistance in the analysis of the accelerometers / gyroscopes. The authors would like to thank Dr. J. Leon and Dr. P. Cyrus for their financial support of this project.

\section{References}

[1] Astin, A. (1993). What Matters in College? Four Critical Years Revisited. San Francisco, California, United States of America: Jossey-Bass.

[2] Light, R. J. (2001). Making the Most of College. Cambridge, Massachussetts, United States of America: Harvard University Press.

[3] Light, R. J. (1992). The Harvard Assessment Seminars: Second Report. Cambridge, Massachussetts, United States of America: Harvard University Press.

[4] Hake, R. (1998). Interactive-Engagement vs. Traditional Methods: A Six-Thousand Student Survey of Mechanics Test Data for Introductory Physics Courses. American Journal of Physics , 66 (1), 64-74.

[5] Chipworks [Online] [Cited: April 26, 2011] http://www.chipworks.com

[6] STMicroelectronics Website [Online] [Cited: April 26, 2011] http://www.st.com/stonline/books/pdf/docs/13951.pdf

[7] STMicroelectronics Website [Online] [Cited: April 26, 2011] http://www.st.com/stonline/books/pdf/docs/17116.pdf 